\title{
Huellas en un cuerpo: La Prieta de Gloria Anzaldúa. Cuerpos y fronteras
}

\section{Traces in a Body: La Prieta, by Gloria Anzaldúa. Bodies and borders}

\section{Rastros no corpo: La Prieta, obra da Gloria Anzaldúa. corpus e fronteiras}

Sharon López-Céspedes

Académica

Instituto de Estudios Latinoamericanos

Universidad Nacional

Costa Rica

Recibido: 2 de septiembre, 2016

Aceptado: 5 de diciembre de 2016

\section{Resumen}

Gloria Anzaldua (1942-2004) escritora lesbiana-feminista chicana. La Prieta, su ensayo autobiográfico, se publicó en Esta puente, mi espalda. Voces de mujeres tercermundista en los Estados Unidos, en 1988. El presente ensayo transita por las letras y pensamientos de esta mujer chicana, latinoamericana, mexicana, mestiza y lesbiana,

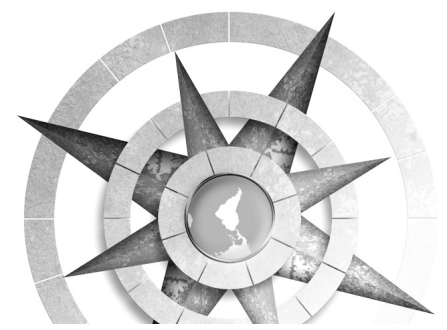

quien analiza y vive las muchas fronteras que atraviezan y penden sobre las humanidades femeninas.

Palabras clave: feminismo chicano, Gloria Anzaldúa, La Prieta, ensayo, pensamiento feminista latinoamericano, pensamiento fronterizo

\section{Abstract \\ Gloria Anzaldua (1942-2004) Chica- na-lesbian, and feminist writer. The auto- biographical essay "La Prieta" was published}


in Esta puente, mi espalda. Voces de mujeres tercermundista en los Estados Unidos [this is the Spanish version of This Bridge Called My Back: Writings by Radical Women of Color, translated and adapted by Ana Castillo and Norma Alarcón], in 1988. This essay examines the literature and thoughts of this Latin American, Mexican, Chicana, mestizo, and lesbian woman. She lived and analyzed several intersections that hang over feminine humanities, and are experienced by them.

Keywords: Chicano feminism, Gloria Anzaldúa, "La Prieta", essay, Latin American feminist thought, border-line thought

\section{Resumo}

La Prieta [Na Preta], é um ensaio biográfico da Gloria Anzaldúa (1942-2004), a escritor chicana, lesbiana e feminista, submerge-nos na historia vivida, íntima, doente y rebelde de momentos na sua vida que desde o seu nascimento marcam e atravessam seu corpo, a partir de construções sociais e culturais, que determinam o tratamento que recebem os corpos pela cor da pele, nacionalidade, o linguajem e o sexo. Neste texto exploram-se geografias corporais, a través das imagines fronteiriças que transcendem territórios, os cauís constituem nossa realidade tangível, as experiências e sentimentos que alimentam a imagem desse corpo e as líneas que marcam as lutas neste como processo preciso de descolonização y reinvenção na humanidade das mulheres.

Palavras chave: Feminismo chicano, Gloria Anzaldúa, La Prieta, ensaio, pensamento latino-americano, teorias da fronteira.

¡Tantas son las fronteras que habitan un solo cuerpo! Algunas son tan pequeñas que ni se las nota, invisibles o silenciosas. Otras, en cambio, se yerguen fuertes, bulliciosas, gigantescas; son como los muros construidos para dividir las naciones con sus alambres electrificados y sus rifles apuntando, siempre vigilantes de nuestros movimientos. ¿De qué lado de la frontera estamos? ¿Quién nos apunta con su rifle? ¿Soy yo, el otro, o ambos?

Los cuerpos se mueven de un lado a otro, orilleros, periféricos, escondidos, invisibles, cuerpos habitados por la desgracia de un color otro, de una lengua otra, de un mundo otro. Si tan solo cruzando la frontera el color de la piel o de los ojos cambiara, si tan solo cruzando la frontera, esta lengua, esta cultura, no nos delatara. 
La llamaban prieta por su piel morena, tan oscura, la cual representa la herencia del indio en ella. Cuando nació, nos cuenta que se le "inspeccionó las nalgas en busca de la mancha oscura, la señal del indio, o peor, de sangre mulata" (Anzaldúa, 1989: p. 157).

El color de su piel no era el correcto, no heredó ni la piel pálida, ni los ojos azules, ni tampoco los cabellos rubios de su abuela. En su primer respiro y sin tener consciencia aún de su cuerpo, ya este la marcaría toda su vida, esa piel que evidencia la herencia india que es la herencia mexicana, la herencia latina.

El color de la piel habita en esta frontera que con grandes rótulos anuncia que la piel oscura representa la subalternidad, el sujeto colonizado. Pasamos de bárbaros, a vagos, perezosos, tercermundistas y subdesarrollados. Por suerte se nos confirió el título de seres humanos, allá en una Junta de Valladolid hace unos cuantos cientos de años atrás.

De un revista de vaqueros, la niña aprende que los mexicanos son los empleados, los villanos o las cantineras y de su madre que el sol es la peor desgracia para una niña de piel morena. "No salgas al sol"..."Si te pones más oscura pensarán que eres una india. Y no te ensucies la ropa. No quieres que la gente diga que eres una mexicana puerca", (p. 157), le decía la madre, sin importar que la Prieta, fuera la hija de una sexta generación de tejanos ${ }^{43}$. Si tan solo al cruzar la frontera cambiara el color de la piel; no es donde naces, es del color que naces.

Con tan mala suerte para Gloria Anzaldúa, que no solamente nació bien prieta, hija de mexicanos agricultores, pobres-migrantes sino que, además, nació mujer.

El sexo, esa otra frontera en la que la mujer se mueve sigilosamente, arremete contra su propio cuerpo, ese cuerpo que le recuerda los limites de sus propios deseos, de sus propios pensamientos, de su propio ser. ¿Cómo una vagina puede determinar tanto la vida de ese ser, convertirlo en un cuerpo mutilado, limitado, anulado? Cuerpo que encadenan y encadenas. Cuerpo institucionalizado de la mujer, "animal naturalmente enfermo” dice San Pablo, varón mutilado sugiere Santo Tomás, solo una cosa se requiere de ella, señala Luis Vives (1940): la castidad.

43 La familia de Gloria Anzaldúa vive en Texas desde antes de 1847 , por lo que como señala Marisa Belausteguigoitia (2009), en su artículo Borderlands/ La Frontera: el feminismo chicano de Gloria Anzaldúa desde las fronteras geoculturales, disciplinarias y pedagógicas, ellos estaban en Texas cuando el territorio pertenecía todavía a México, a pesar de ello, sin ser migrantes, se asumen como tales 
Pura, casta, virgen, la mujer ideal. El espejo de la Prieta es su madre, en la que reconoce a esa villana-víctima, que puede ser la mujer-madre. A los siete años le amarraba los senos con una faja de algodón ajustada y le aseguraba un trapo doblado en las pantaletas, "mantén las piernas cerradas, Prieta" (p. 160), le decía.

Piernas cerradas, mente cerrada, boca cerrada: la mujer ideal. El cuerpo de una mujer, atrapado y controlado, un cuerpo colonizado, fragmentado, carente de voz; el cuerpo se convierte en centro de lucha del oprimido y del opresor; es necesaria la rebeldía, el grito valiente, la reconstrucción de otro yo, la búsqueda de otros espejos, mis espejos.

Mujer: ¿cómo encontrarse a sí misma? ¿Cómo aprender a mirarse, y mirarnos con amor, con empatía, y tal vez, con un poco de compasión? ¿Cómo construir lealtad con nuestro género? ¿Cómo perdonarse y perdonarlas?

La prieta no cerro las piernas, como hubiese querido su madre, pero mucho menos la mente o la boca. "Machona, india ladina" (p. 162) la llamaba la madre, por su forma de vestir y hablar; "frígida", un novio; y, "puta" y "jota" ${ }^{44}$ su familia. La rebeldía y la insumisión, su

44 En México, joto o jota se le llama a los homosexuales y lesbianas nombre y apellido; y es que ¿desde dónde sino es desde el cuerpo que puede iniciar la mujer cualquier lucha emancipatoria? Recuperar ese cuerpo que nos han arrebatado, sobre el que no tenemos voz o decisión.

El pecado de la Prieta estaba envuelto en una tortilla (Anzaldúa 1989). En la escuela, les llamaban "tortilleros" en la escuela. ¡Cómo no querer cambiar la tortilla por el pan blanco, los tacos por hamburguesas!

La vergüenza de ser latinas. Fuimos educadas para sentirnos menos, menos que el hombre, menos que la mujer blanca. Nuestra cultura latina, herencia de una madre que fue ultrajada hasta lo más profundo de sus entrañas, despojada de sus riquezas, de su lengua, de sus tradiciones.

Los restos de esta cultura habitan en los cuerpos y eso nos avergüenza, como la victima que se siente culpable y avergonzada de su violación, que se revictimiza, traicionadas por ese inconsciente socializado del que habla Castoriadis (citado por Fernández, 2012) ${ }^{45}$

45 De acuerdo con Castoriadis (citado por Fernández, 2012) el Yo, el Superyó y el Ideal del yo son impensables, salvo como productos del procesos de socialización y no hay posición entre inconsciente y sociedad. El inconsciente es una creación social y una formación histórico-social en cada singularidad, no podemos pensar la socialización como una simple suma de elementos externos a 
Así, la vergüenza es la madre, una vez más, el espejo, mujer con la que la Prieta se reconcilia más adelante, en quien reconoce a la mujer luchadora, presente siempre en su vida. Citando el poema de Nellie Wong, le dice a su madre: "Amá, óyeme ahora, cuéntame tu historia, otra vezy otra vez" (Anzaldúa, 1989: p. 163)

La reconciliación con la madre, representa por un lado, reconciliarse con la mujer, con una misma, con esa voz que juzga, señala, castiga, y, por el otro, reconciliarse con su cultura, sus tradiciones, sus costumbres, reconstruir el habitus $^{46}$ del cuerpo, romper los barrotes que determinan nuestras percepciones de lo bueno y lo malo, de lo bello y lo feo, repensar la relación con nuestro cuerpo, reescribir el texto del cuerpo. Un proceso doloroso.

"El doctor jugó con su navaja. La Chingada abierta, violada por la vara del hombre blanco" (p. 164) cuenta la Prieta. El doctor es el hombre blanco, el poder de dominación, la navaja es el elemento simbólico de la masculinización y la feminización

un núcleo psíquico que permanece inalterado, sino que sus efectos están inextricablemente tejidos a la psique.

46 Utilizo el término que usa Bourdieu, habitus, como un sistema de disposiciones que integran todas las experiencias pasadas y funcionan como una matriz estructurante de nuestras percepciones y apreciaciones ante la vida. Véase: "Producción de habitus y violencia simbólica”, de Marta Fernández Boccardo (2012) En: Mujeres que Callan. Argentina: Editorial Entreideas. de los cuerpos y la chingada, el útero, la mujer, su cuerpo. La chingada, dice Octavio $\mathrm{Paz}$ (1950: s/p): "[a]nte todo, es la Madre. No una Madre de carne y hueso, sino una figura mítica... es la madre que ha sufrido, metafórica o realmente, la acción corrosiva e infamante implícita en el verbo que le da nombre". (http:// www.hacer.org/pdf/Paz00.pdf)

"Es una palabra mágica" continúa Paz, por un lado, si se ve como verbo, chingar implica violencia, "salir de sí mismo y penetrar por la fuerza en otro"; si por el contrario se ve como adjetivo, expresa pasividad:

Lo chingado es lo pasivo, lo inerte y abierto, por oposición a lo que chinga, que es activo, agresivo y cerrado. El chingón es el macho, el que abre. La chingada, la hembra, la pasividad, pura, inerme ante el exterior. La relación entre ambos es violenta, determinada por el poder cínico del primero y la impotencia de la otra. La idea de violación rige oscuramente todos los significados. La dialéctica de "lo cerrado" y "lo abierto" se cumple así con precisión casi feroz (http:// www.hacer.org/pdf/Paz00.pdf)

¿Cuántas mujeres están enterradas debajo de mí? ¿Cuáles mis luchas, cuales las de ellas? No sé si reconozco todas las voces, pero reconozco las voces del 
dolor, de la violencia que ha marcado nuestros cuerpos, del golpe, de la palabra, de la mordaza. Veo en sus ojos, mis ojos, el miedo, a existir, existo a través de una mirada, la mirada del otro. Veo los cuerpos moverse, inhabitados, tantos recovecos nos son desconocidos, tantas sus marcas y lunares, que aún hoy no nos pertenecen.

También reconozco otras voces, las voces de lucha, de emancipación, voces desde la orilla y la periferia. Reconozco el grito de liberación, el llanto de alegría, el canto, la palabra afectiva, el abrazo solidario. Son tantas las voces y estas nos habitan a una y a todas.

Es necesario despojarse de todo, abrir los ojos, reconocer el cuerpo, perderse y encontrarse en él una vez, otra vez y otra vez, hasta que me convierta en cuerpo y el texto del cuerpo sea mi voz, mis pensamientos, mis sentimientos, mis sensaciones, un cuerpo habitado por mí.

Una mujer está enterrada debajo de mí,

Sepultada por siglos, supuesta muerta.

Una mujer está enterrada debajo de mí.

Oigo su suave murmullo la escofina de su piel pergamino combatiendo los pliegues de su mortaja.
Sus ojos por agujas picadas

sus párpados, dos polillas

aleteando.

-de "A Woman Lies Buried Under Me"

(Una mujer está enterrada debajo de mí) (Anzaldúa, 1989: p. 167)

\section{Referencias}

Anzaldúa, G. (1989). La Prieta. En: Esta puente, mi espalda. Voces de mujeres tercermundistas en Los Estados Unidos. [Cherie Moraga y Ana Castillo Eds. Ana Alarcon, Trad.]. Estados Unidos: ISM Press/Editorial Ismo.

Belausteguigoitia M. (2009). Borderlands/La Frontera: el feminismo chicano de Gloria Anzaldúa desde las fronteras geoculturales, disciplinarias y pedagógicas. Debate Feminista, Vol. 40 (Octubre), pp. 149-169.

Fernández Boccardo, M. (2012). Mujeres que callan. Argentina: Editorial Entreideas.

$\mathrm{Paz}$ O. (1950). El Laberinto de la soledad. Primera Edición (Cuadernos Americanos) México, D. F.: Fondo de la Cultura Económica. Consultado en: http://www.hacer.org/pdf/Paz00.pdf

Vives, L. (1940). Introducción de la mujer cristiana. Argentina: Colección Austral Espasa-Calpe. 